\title{
China's Grand Canal. Strategies for Sustainable Urban Development in China
}

\section{Andrea Degli Angeli}

\begin{abstract}
China has had to deal with the huge architectural and urban development challenges created over the past fifty years. China's economic growth model has been based on accelerated consumption and manufacturing, with inevitable and significant environmental and social consequences. The model discussed in this paper seeks to employ the principles of sustainability in a specific urban development context: the massive Beijing-Hangzhou Canal, the longest artificial waterway in the world. The model simulates a macro strategy for the redevelopment of this ancient water system utilizing and adapting highly successful traditional Chinese planning methods for urban, wetland and rural areas. Elements of this model could serve as the basis for effective future Chinese urban development in similar contexts. China has already begun actualizing policies and strategies to address major concerns about environmental and social issues. The proposed model is intended to contribute to this endeavour and to promote sustainable growth in the most populated country in the world. The project outlined in this paper shows that the planning elements that inspired Marco Polo's admiration for Chinese cities are still highly relevant in a country increasingly damaged by inappropriate and standardized international urban development approaches.
\end{abstract}

Keywords: sustainability, urban development, future cities, China, grand canal 
The words Grand Canal immediately make us think of the beautiful Venetian canal that attracts people from all over the world to marvel at the extraordinary architectural landscape created over the centuries. The urban morphology of Venice is based on the land-water dichotomy, and over centuries it developed and maintained an urban form in perfect harmony with its natural environment and that which surrounds it. The Grand Canal, considered the backbone of this urban plan, involved the creation and design of special architectural models. It is one of the most complex, studied, and admired systems in the world.

After the military and economic decline of the eighteenth century, Venice was no longer a major political and economical power. In spite of this, the city was able to preserve the characteristics that made her famous in the world and, taking advantage of the beauty of this unique urban landscape, it transformed itself gradually from a market town into a tourist destination. Venice successfully addressed the issue of architectural conservation during the nineteenth and twentieth centuries, when elsewhere the massive economic changes that were occurring led to demolition of historic buildings and entire areas, followed by reconstruction and expansion using poorly planned and regulated urban schemes. The purpose of this paper is not to deal with Venice critical issues; rather the question is what can be learnt from Venice that can be applied to current and future urban planning. The present paper explores how the application of these principles, with the enhancement of contemporary tools and techniques, can develop new boundaries for the human landscape at a time of profound global change and degradation, and in so doing give to future generations opportunities to live in attractive new urban landscapes that are in harmony with Earth's delicate ecosystem.

\section{CHINA'S GRAND CANAL}

The Chinese Grand Canal, in Chinese Pinyin Jing-Hang Yunhe (BeijingHangzhou Grand Canal), and the Great Wall were the two major projects of ancient Chinese civilization, both acting as symbols of its power and sophistication. With a length of $1,794 \mathrm{~km}$ (about 1,115 miles), it is the longest artificial waterway in the world. (Fig. 1). It is not strictly a canal but rather a system of connected waterways. In China, numerous watercourses, from $486 \mathrm{BC}$, were excavated, constructed, sanded and drained all over a period of 2,000 years, during which successive dynasties and emperors invested in the river system. These waterways played also a vital role in the reunification of China. For centuries the easy navigability of the water network allowed for the transportation of people, goods and materials, as well as the spread of knowledge and culture.

The development of this commercial network strengthened China's economy and its relations with the rest of the world and allowed 


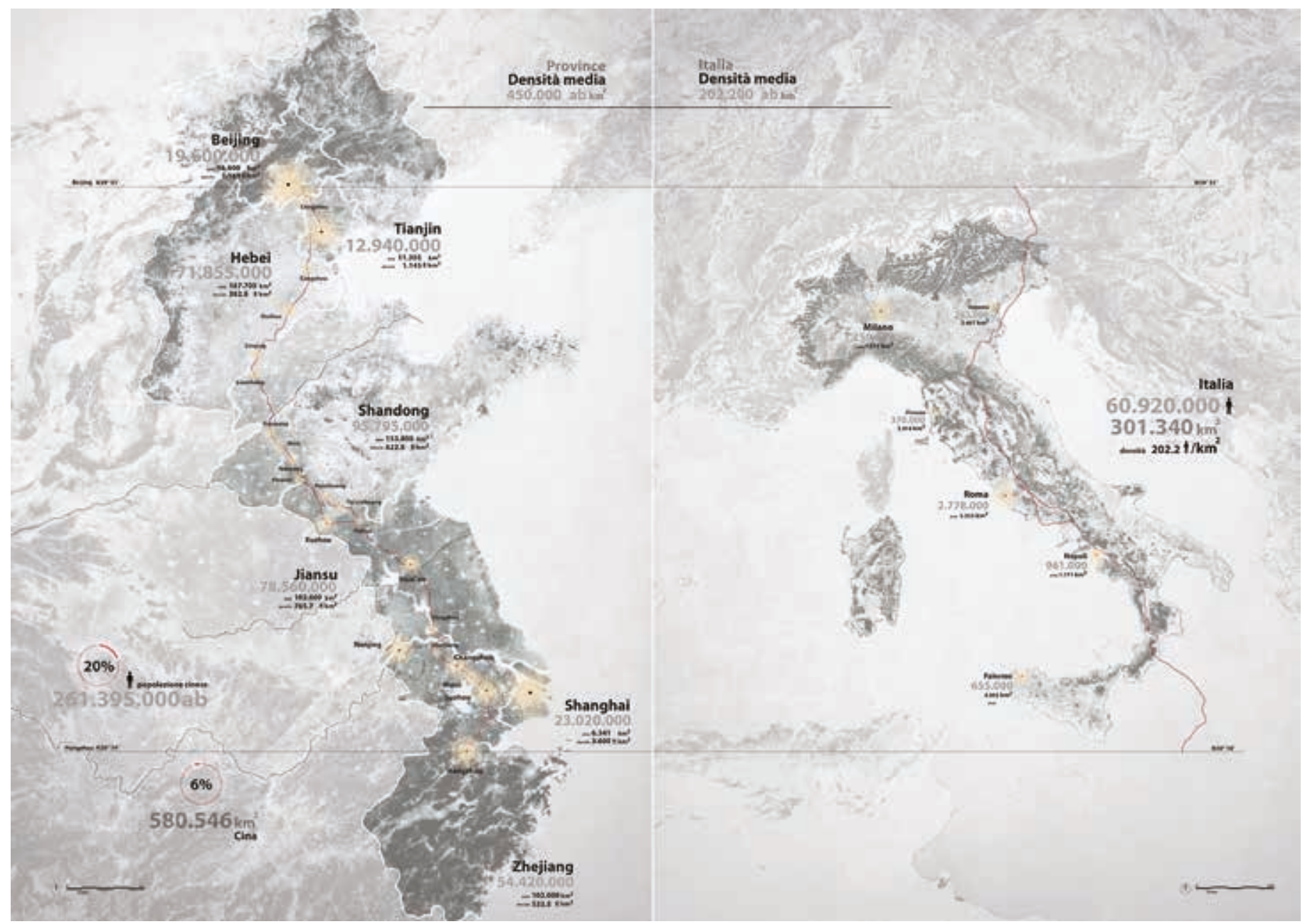

Figure 1. Comparison between the China's Grand Canal and Italy.

wheat and rice from the richest province of the Yangtze (Chang) to be transported to feed the standing armies near the capital in the north; in the Tang Dynasty about 200,000 tons of grain were transported yearly. The countless transformations that occurred over time profoundly altered the canal's path. In 2008 the complete network was under consideration by UNESCO as a World Heritage Site, and there are on-going studies and research on the difficult task of rebuilding the geological, hydrological and archaeological sites within the canal network. In short, the Grand Canal is a colossal achievement and demonstrates key principles regarding the transformation of the territory by man, in his relationship with nature, being of the utmost relevance today.

\section{CHINESE URBAN MORPHOLOGY}

Before going any further, it is vital to examine what features of Chinese culture, cities and homes can be employed to avoid inappropriately standardized and decontextualized planning. 


\section{The Traditional Chinese City}

The rigid nature of traditional Chinese space definition and urban planning reflects the features of a culture that based its values on Confucianism, with space organisation following a superior-inferior hierarchical model that reflected social structure. This is a model determined by the symbolism that was an integral part of both cosmology and imperial ideologies, and it was applied to the organization of cities and towns as well to regulating life inside the Chinese household. The family, not the individual, acted in public life. The strict geometry, the absolute symmetry, and the inflexible hierarchy that were rigorously applied in the ordering of the Chinese home are an architectural representation of the equally strict doctrine-based order that governed family and public life.

The key elements that made up the ideal Chinese city are enclosing walls, an orthogonal road layout, the central location of the palace, a south-north processional axis, the preferred orientation of the building to the south, the similar height of buildings, and the courtyard typology as a framework for all buildings. The main difference between Western and Chinese philosophy, with regard to settlement and building, is that since ancient times Western culture has focused on changing environments to suit need, whereas the Chinese focus until very recently was on ensuring that human activity does not disturb the cosmic balance, while endeavouring to enter into a harmonious relationship with one's surroundings.

The combination of these factors led to the identification of two urban structures that are very different from a morphological point of view. In the West we see more complexity, with a rich and varied urban structures and articulated spaces full of public buildings - an expression of a culture open to foreign contributions. In contrast, Chinese society was more closed with an inherent desire to maintain its own culture. This was reflected in planning and produced morphology of rigidly homogeneous spaces governed by hierarchy.

\section{The Traditional Chinese House}

Traditionally, in China the relationships that govern the distribution of spaces on an urban scale also govern the layout and construction of houses. As we have seen, it is the family, not the individual, that is of primary importance in Chinese society.

The single-family courtyard home was the most suitable residential typology for accommodating a social microcosm as it embodies a dichotomy: the intimate space for private use totally separate from the outside world. The Chinese courtyard house, which is either square or rectangular, is a far cry from the ideas behind western building as there is an absence of volumetric compactness, and because of the major role open spaces play. It is characterized by a set of articulated formal spaces, (including additional smaller courtyards and pavilions) that are enclosed and volumetrically autonomous, and which are independently placed on the sides of the large 
central court, in a strictly interrelated and predetermined arrangement. It is important to note that the aforementioned type of courtyard house was abandoned in the West 2,000 years ago and that the Chinese house changed and developed considerably, going from a single family home to a multiple family dwelling through a process of cell doubling, fragmentation of the original unity and the introduction of lots of public paths linking the new courtyard in a process called "insulization." In today's cities, however, with the shift from the large extended family to a single core family, many traditional houses were split up into apartments, and the original spatial organisation has been altered or obscured.

The significance of Confucian ideology and the resulting social order in China has diminished with the change in family structure and socio-cultural values in Chinese society that have occurred since 1900, as well as the advent of increased individualism influenced by Western culture and its socio-economic dynamic. Finally, if in ancient Chinese cities, as well as those in Europe, the land use was mixed (residential and commercial), with the recent economic development land uses have changed by allocating specific areas for residence, trade, industry and green spaces, further contributing to disrupt the spatial configurations of the urban fabric of Chinese cities.

\section{Elements of the Courtyard House: the Fence}

The siheyuan, the traditional Chinese courtyard house, was a house enclosed by a high wall without windows so as to prevent any form of contact between the inside and the outside worlds. It had a single level and a rectangular plan and was characterized by an axis, which functioned both as a spatial organizer and a place for social activities.

In keeping with Confucian principles, rooms and spaces were laid out in a hierarchical order with respect to the central axis. The closed-open, internalexternal, public-private dichotomies inherent to Chinese construction and architectural culture are all represented by the external wall element. A separate private world characterised by neatness, colour and vegetation stood in contrast to the anonymous and impersonal public space beyond it with its busy roads, or, in the case of Suzhou, its canals. While the courtyard house is not the only Chinese residential solution, it remains the most significant and its principle of interior separation is noteworthy.

Over a long period of time various factors have contributed to less rigid enclosure, nonetheless the concept of enclosing and a surrounding wall are still key factors in Chinese architectural culture and the use of space.

\section{Elements of the Courtyard House: the Garden}

The empty space of the courtyard, in traditional Chinese homes, is just as important as the buildings themselves. In the traditional urban context, as well as streets and alleys, courtyards have also represented the virtually only form of open space in a crowded urban context. In traditional houses, each small courtyard and, in some cases, private gardens as well, were mainly shared 
only by members of each resident families. The development of gardens within these courtyards is an integral part of Chinese culture that encourages closeness to nature and peace as an antidote to urban confusion. For this reason, courtyards gardens almost always contain elements that refer to a natural landscape: it is not surprising then that in Chinese calligraphy the character for garden is composed of a tree (a trunk with branches) enclosed in a square (a courtyard space and external wall). The natural world was central to Chinese art and gardens, which were works of art carefully created with attention to rhythm, scale, balance, harmony, proportion, and unity. Man has for centuries spoiled the natural landscape in which he lived, transforming it at will for human activity and the creation of settlements. The importance of Chinese gardens shows a vital respect for nature and the need to remain in contact with the natural world.

\section{CHANGES}

\section{Demographic and Economic Development}

In 1950 China's population was about 554 million people, in 1990 it reached the one billion mark and in 2013 it stood at around 1.3 billion. The United States Department of Economics and Social Affairs estimates that the population will reach its peak in 2050 with 1.4 billion people before levelling off and dropping slightly to around 1.2 billion in 2100 .

The population of China represents around one fourth of the world population. The significant population growth that has occurred in the last fifty years is attributed to the strong improvement in the economy, which has experienced an average growth rate of $10 \%$ per year for more than twenty years. China now has a GDP second only to the United States, with predictions that it will surpass the US around the year 2040. (Fig. 2).

This economic miracle, that has been on-going notwithstanding the global financial crisis, has resulted in China facing one of the most significant social and cultural transformations in its long history. A very large number of young people are leaving rural areas, where most live on the equivalent of $\$ 2$ a day, to go to the cities looking for work opportunities in factories and elsewhere. Today, with major participation by foreign companies, China has significantly increased production in high technology sectors and is currently the third biggest investor in research and development in the world. China's massive coal, oil, mineral and uranium resources have been a significant factor in the success of its industrial development.

In many respects China has to deal with the grave problems that occurred during the Industrial Revolution, as unbridled development using a nineteenth-century industrial model has brought vast wealth, but with devastating consequences for natural ecosystems that will have a massive impact not only on China, but also the entire world. While the Chinese government is aware of these huge problems and is slowly beginning to take remedial steps, it still largely continues to support this model, which allowed China to become a major world financial and military power. 


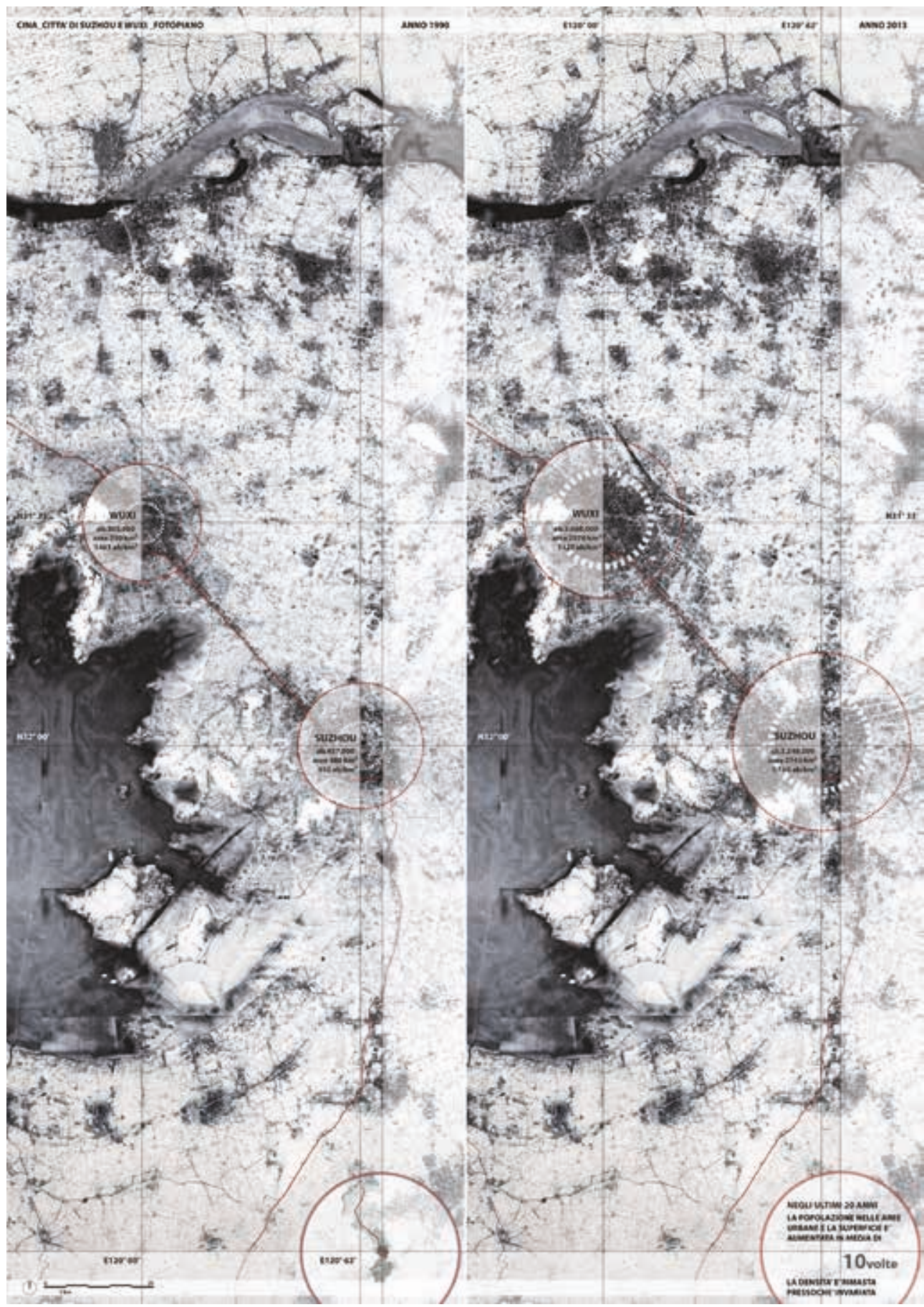

Figure 2. Human change analysis. Comparison between 1990-2013.

\section{Natural Resource Consumption: Water}

This kind of economic growth does not come without problems: water supply and water pollution are two of China's most serious and complex challenges. China's renewable water supply results in an annual $2,140 \mathrm{~m}^{3}$ per capita, compared to 1,720 in India and over 10,000 in the United States. 
However, as it is the case for other countries, water distribution is uneven: for example, supply is very good south of the Yangtze, while many areas in the north have poor supplies and are almost barren.

The large river system in China flows mainly from the Tibetan mountains, crosses the whole of China, flowing into lakes, going deep beneath the surface to feed aquifers, before finally arriving at the sea in the far east of the country. The manmade system of canals that constitutes part of the Grand Canal diverts the natural watercourse, and flows from south to north (instead of from east to west) thus allowing the canal to cross a considerable number of other canals; a radical concept that the Chinese historians have described as "a brilliant act of madness."

This system has worked very well until the present day and represents a huge communication and transport system that transfers resources from the agricultural basin of the Yangtze to the political and administrative centres in the north, where millions of people live today. However the non-uniform distribution of water and the growth of demand in cities are having a strong social impact: in the north of the country, where about $50 \%$ of the population live, there is access to only $14 \%$ of water resources.

As a major part of China's food self-sufficiency policy, the government pushed to transform the northern plain into a large area for agricultural production. This plan required groundwater to be pumped out of aquifers at a rate faster than these are naturally able to be replenished, causing a rapid decline of water resources. Obtaining water this way has led to the loss of wetlands, as well as seriously damaging streams and canals, with a huge impact on ecosystems and the geological stability of the territory. In the provinces of Hebei, Shandong and Jiangsu, water use is also greater than its availability, and the same happen in the municipalities of Beijing and Tianjin; the only exception are the areas around the Grand Canal and in the province of Zhejiang, in both of which availability is greater than the demand.

According to estimates, $70-80 \%$ of national water consumption is for industry and agriculture. Demand in residential areas, which in 1980 was almost insignificant at about $1.5 \%$ of the total, is currently $6 \%$ due to rapid population growth, with consumption increasing from 7 to 32 million $\mathrm{m}^{3}$ per year. (Fig. 3). Large demand in urban areas combined with inadequate infrastructure and bad management by local governments has led to water shortages in more than 600 cities across China, as well as leaving more than $\mathbf{3 0 0}$ million people, who live in rural areas, without access to safe drinking water.

Additional negative factors are weak legislation and ineffective institutions at all levels of government (from national to local), poor and sometime corrupt tender procedures and institutional rivalry. To remedy the situation would require a strong centralization of management and control, but this is highly unlikely to happen in the foreseeable future due to the impotence 


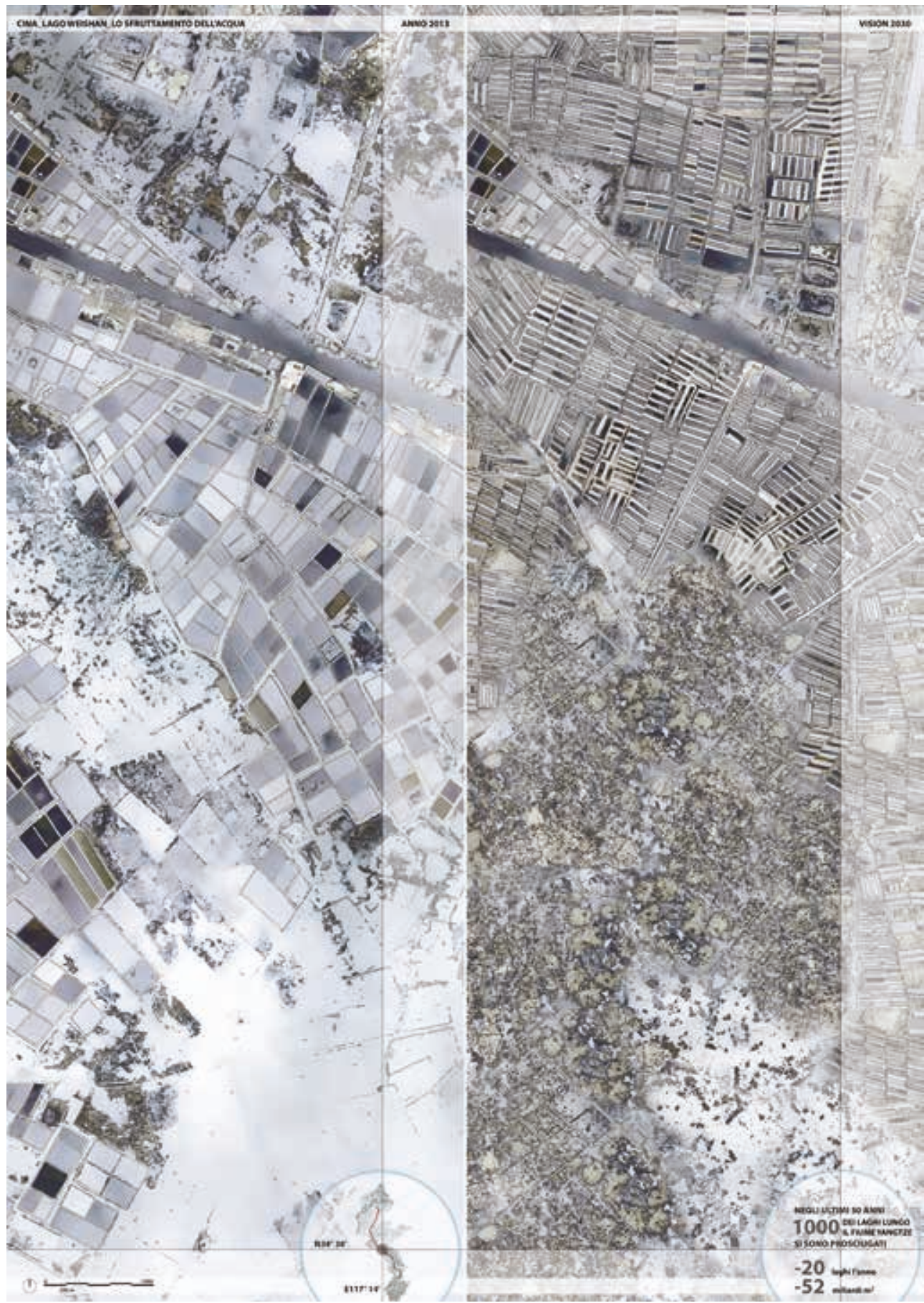

Figure 3. Water change analysis, future projection. Comparison between 2013-2100.

of the central government in reforming regional powers, which are frequently corrupt and supported by powerful vested financial interests. A traditional engineering culture is widespread, and the usual response to water shortages is to invest heavily in large projects rather than to research and implement new models or improve management. Notable examples is the 2002 approval for a pipeline from the Yangtze to the north of the country, 
which has a capacity of 45 billion $\mathrm{m}^{3}$ of water per year, and the investment in new seawater desalination plants in the vicinity of the city of Tianjin.

\section{Energy and Emissions}

In the last few years, China has become the world's largest polluter, exceeding even the United States. The damage caused by pollution and environmental degradation is to such an extent that it threatens the very fabric of society. China has thirteen of the most polluted cities in the world. In addition to air and water pollution, a tenth of the cultivated land is estimated to be contaminated by heavy metals.

Unbridled growth without adequate controls and the application of suitable technology and techniques has left the nation with an enormous environmental deficit. Key factors are rapid urbanization and the use of coal as the main energy source, which recorded an increase from $10 \%$ of supply in 1961 to $54 \%$ in 2008 . The nation has consumption about 2 and a half times its bio-capacity. The vast emissions of greenhouse gases have already crossed the sustainability threshold in twenty-five Chinese provinces. A considerable environmental problem is that the backwardness of rural areas, which both exacerbates the problem and hampers the implementation of solutions. The average temperature in China in the last century, grew by between 0.6 and 0.8 degrees Celsius and in the last 50 years, the sea level has increased by 1-2 mm per annum. Climate change has made China vulnerable to droughts, floods, tropical cyclones and heat waves. (Fig. 4).

Although China still relies heavily on coal to produce two-thirds of its primary energy, in recent years there has been a rapid rise in the use of alternative energy sources: in particular, hydropower, wind power, solar, and biomass power. Nevertheless, the energy supplied by renewable sources is equal to only $8 \%$ of total output. The $12^{\text {th }}$ Five-Year Plan has set aside massive subsidies and investment with a target of $15 \%$ of budget by 2020 to be used for sustainable energy sources such as biomass energy, solar energy and in particular wind energy. In contrast, hydropower is expected to have a slight decrease in future funding because of the environmental problems caused by the huge works that they entail. It is important to note that China's main priority is continued economic growth and developing backward areas of the country and significant transformation and damage will continue. We will have to wait to see if current and future measures to protect the environment will have any significant effect.

\section{CHINA TODAY}

With continued rapid growth, China is currently experiencing deep political, economic and socio-cultural changes. The process of globalization and the entry of foreign capital into the country have caused profound changes in the morphology of Chinese cities and their culture as a whole. 


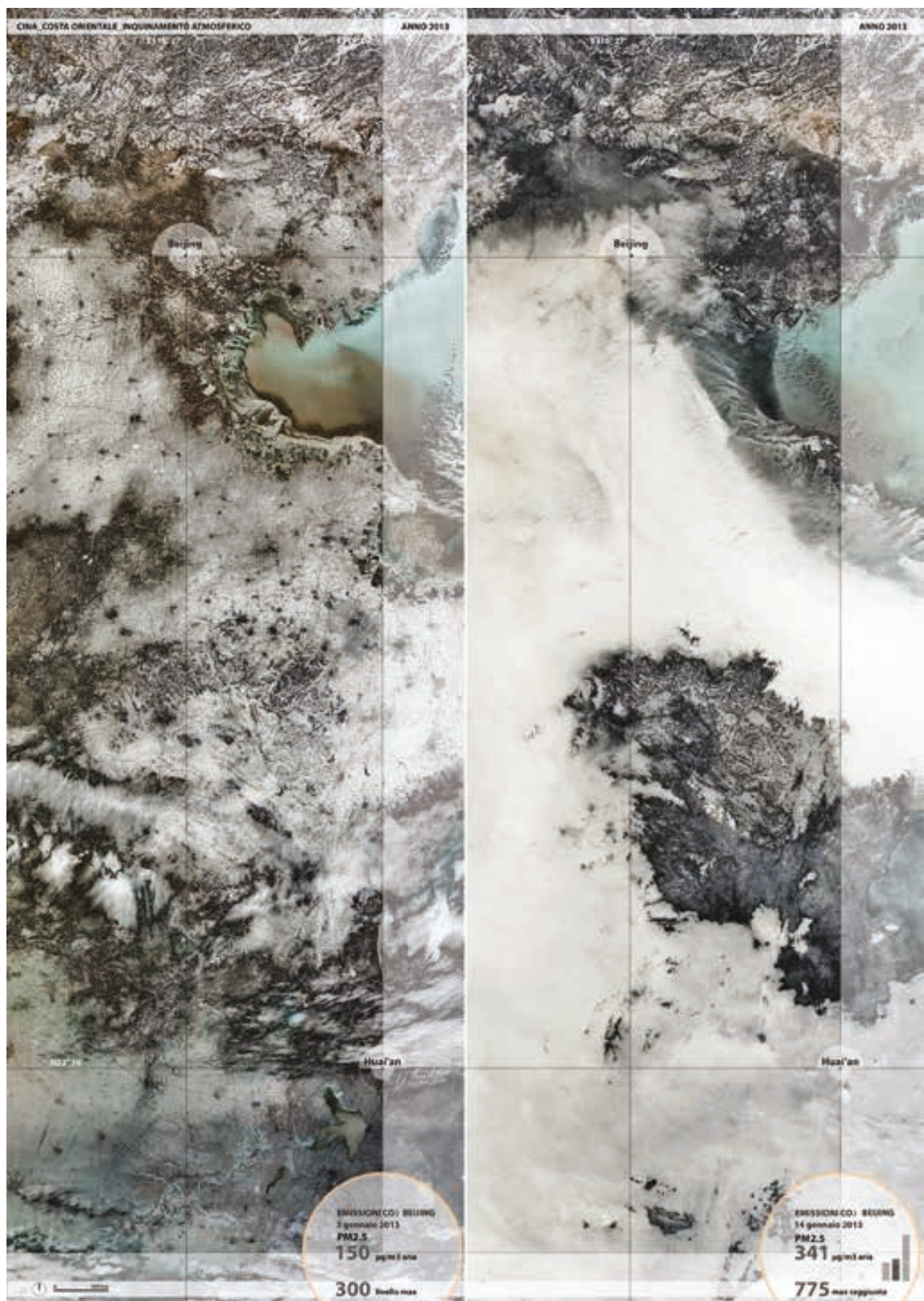

Figure 4. Climate change analysis, pollution increases. Comparison between the normal and the polluted day, year 2013.

The old models were replaced in less than a century, with the preceding scale and the pace of urban development replaced by new models with Western morphological and space characteristics. This fast and relentless transformation has caused Chinese cities to lose much of their identity, with the demolition of old urban areas and their replacement with Western models. These new models are often alien to the local population, as they 
do not contain any of the traditional features of Chinese housing and their focus on traditional Chinese family interplay. In terms of culture, China could be seen as having been "conquered" by the West, given the loss of local character and its replacement by Western urban standardization, which has replaced traditions that had been jealously safeguarded for centuries. Alien design concepts such as residential tower blocks and skyscrapers have been introduced indiscriminately and uncritically and at a greatly accelerated rate since 1980 , causing enormous damage to Chinese design culture.

\section{Planned New Cities}

The construction of new cities is a comparatively new approach in urban Chinese planning, which in previous times was resistant to phenomena of social and urban transformation. Some of the best known projects in progress, such as One City and Nine Towns around Shanghai, seem to affirm the need to recognise that cities have limits in their ability to cope with a continued demand for housing. Given the transfer of large numbers of people from the country to the city, and in order to preserve existing cities, it is necessary to build new cities.

There are basically five criteria that determine the creation of a new city. The first and second criteria are closely related to each other and consist of "geopolitical and dimensional relationships" compared to existing settlements; the third is the "internal articulation of the functional components"; the fourth is the establishment of a "minimum town and city population threshold"; the fifth criterion is the "practicality of realising the project," or at least part of it. In China the construction of new cities is mainly for one or more of three reasons: industrial modernization, constraining urban physical expansion of existing cities and the creation of centres for research and development.

\section{MACRO-STRATEGIES}

\section{Changing Management Opportunity: the Grand Canal as a Macro- Infrastructure}

Success is more likely if we see meeting the challenges created by environmental, climatic, social and cultural changes as opportunities. From this perspective, the processes become an occasion for a new and effective management of territory and resources and also a chance to restore attitudes that are central to a proud and proven heritage. The purpose of this study is to identify a theoretical and applicable model for resource management and change that is also adaptable to territories as a whole instead of the standardised solutions that typically characterize urban development. In developing countries, where rural living often involves hardship, an increase of urban areas can often be seen as a positive aspect as it offers a better life, more opportunities, development, 
innovation and access to services. The real problem is the uncontrolled expansion of these areas. The adoption of the new city model is well intentioned, but the lack of overall strategies will result in the problems with existing cities continuing to occur, What is needed are new settlement schemes that are able to relieve the growing population pressure in and around the growing mega-cities in China, with the advantage that they would offer good living standards, far better use of resources and reduced environmental impact. (Fig. 5).

\section{Settlement Strategy}

The proposal put forth in this paper is that a well-planned development of the Chinese Grand Canal may play a role of fundamental importance. The proposal is to use the canal as the location for new urban spaces on its margins, using a self-sufficient settlement model for the efficient and sustainable use of available resources.

The canal would act as an interregional infrastructural corridor, and the facilitator of large-scale development in new territorial strategies. This would help to control the expansion of the main urban centres, with the canal acting as the backbone of a city system, thus avoiding the radial expansion polycentric model that is characteristic of megacities, and instead employing a polycentric linear model, which promotes exchange, economic development and brings opportunities to the population living in rural areas, all of which are important advantages.

In order to avoid destructive competition between neighbouring administrative areas and the inappropriate influence of speculators and private developers, it is fundamental that this urban development macrostrategy is directly managed by the national government. Furthermore, it is essential that the positioning of these settlements is integrated with local planning so as to ensure appropriate development and to avoid uncontrolled growth. Correct scale of intervention remains essential and will be identified by typology on a case-by-case basis.

Therefore this paper's proposal involves the identification of four stages for determining this strategy. These are as follows:

- The First Phase would be a reorganisation of the existing layout and the establishment of an infrastructure, as well as the design of a transport system for people, goods and resources.

The purpose of this phase is to spread the production, use and management of resources (water, energy, food, industrial and urban waste disposal, and recycling) throughout a single system that is able to integrate them. This would reduce the size of single areas within the infrastructure, and locate production in order to reduce dispersions that result when there are large resource displacements, thereby contributing to the preservation of land and the environment. 
- The Second Phase would involve a linear process of urbanization, whose layout would be determined by infrastructure alignment. To attract settlers to new communities, key locations would be identified as candidates for urban development based around resource and service structure hubs (e.g. water purification, agriculture, employment opportunities, etc.).

- The Third Phase would involve the replacement of the existing inefficient road system with a new simplified system so as to better connect the main existing urban centres with the new centres created along the Grand Canal system by Phase Two, with the additional benefit of decreasing the amount of land covered by impermeable road surfaces, thus reducing flooding, land and water wastage.

- The Fourth, and final, Phase would consist of regional biotic corridors throughout and around the infrastructure network and the new urban centres. This would make a contribution against climate change and provide recreational areas and animal sanctuaries, as well as mitigating high temperatures.

\section{CONTEXT DECLINATIONS}

\section{Drivers}

In order to determine a model that is not limited to offering a single solution it was essential to identify some indicators for defining the size of new urban projects and the relationship that they have with existing urban areas and the local environment, and the relationship between functional spaces and the established minimum and maximum thresholds.

The projects are customized to variables, and to address the main problems encountered. For this purpose 3 leader elements have been chosen; human resources, water, and energy. Using these 3 factors we are able to identify usable technological elements for site conditions. These would be made more efficient with suitable new technologies and new public and private investments.

\section{Macro-Area Individualization}

Once an urban plan strategy and a general change-management model are established, it is necessary to assess applicability and feasibility of the model by identifying different contexts and elements considering the geographical, climatic, and geopolitical diversity along the entire canal's network. The proposal focuses on three strategies for implementation on a territorial scale on the basis of area classification. (Figs. 6, 7 and 8). 


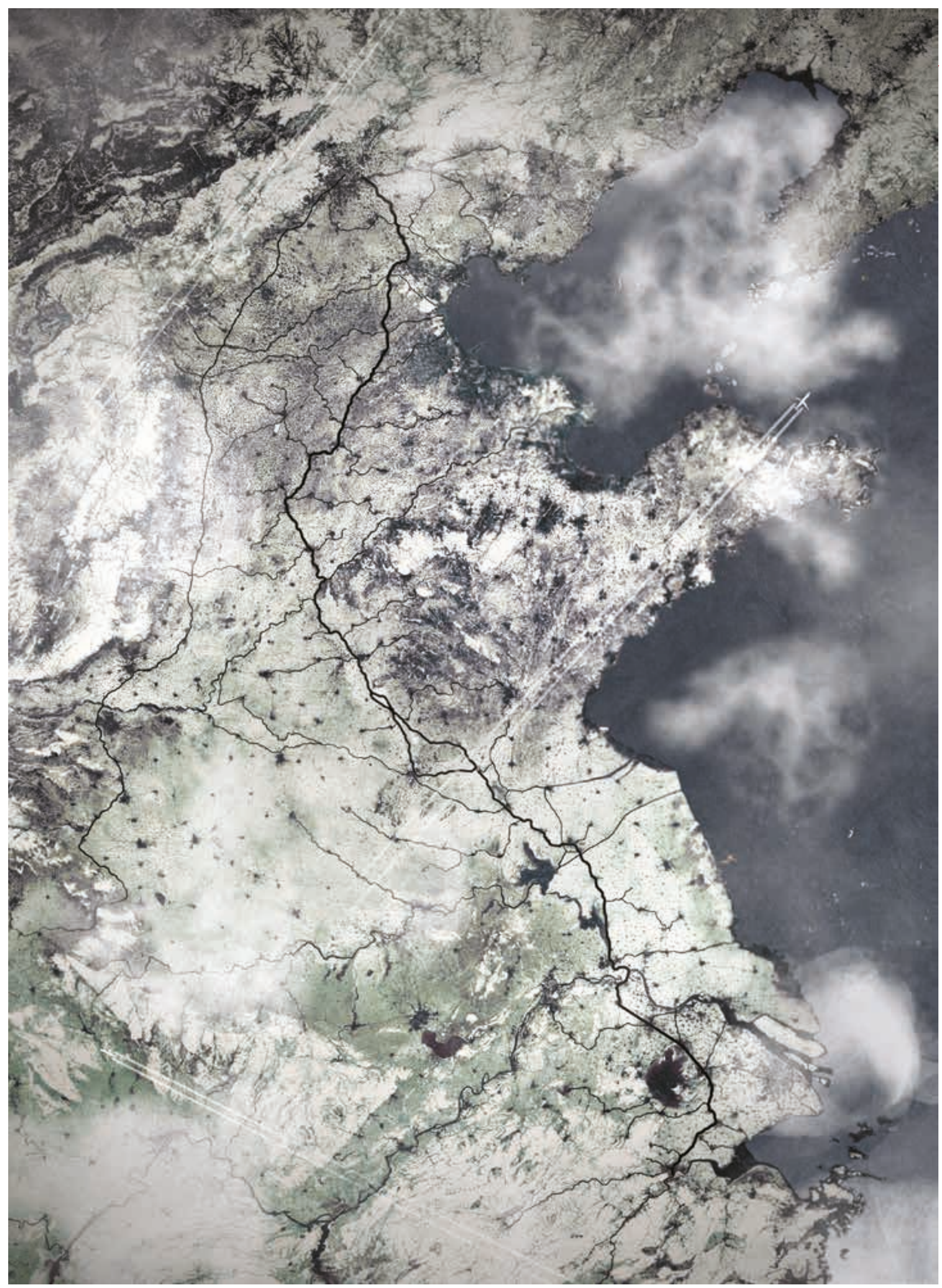

Figure 5. China's Grand Canal, the entire rearranged network. Aerial view, 2100. 


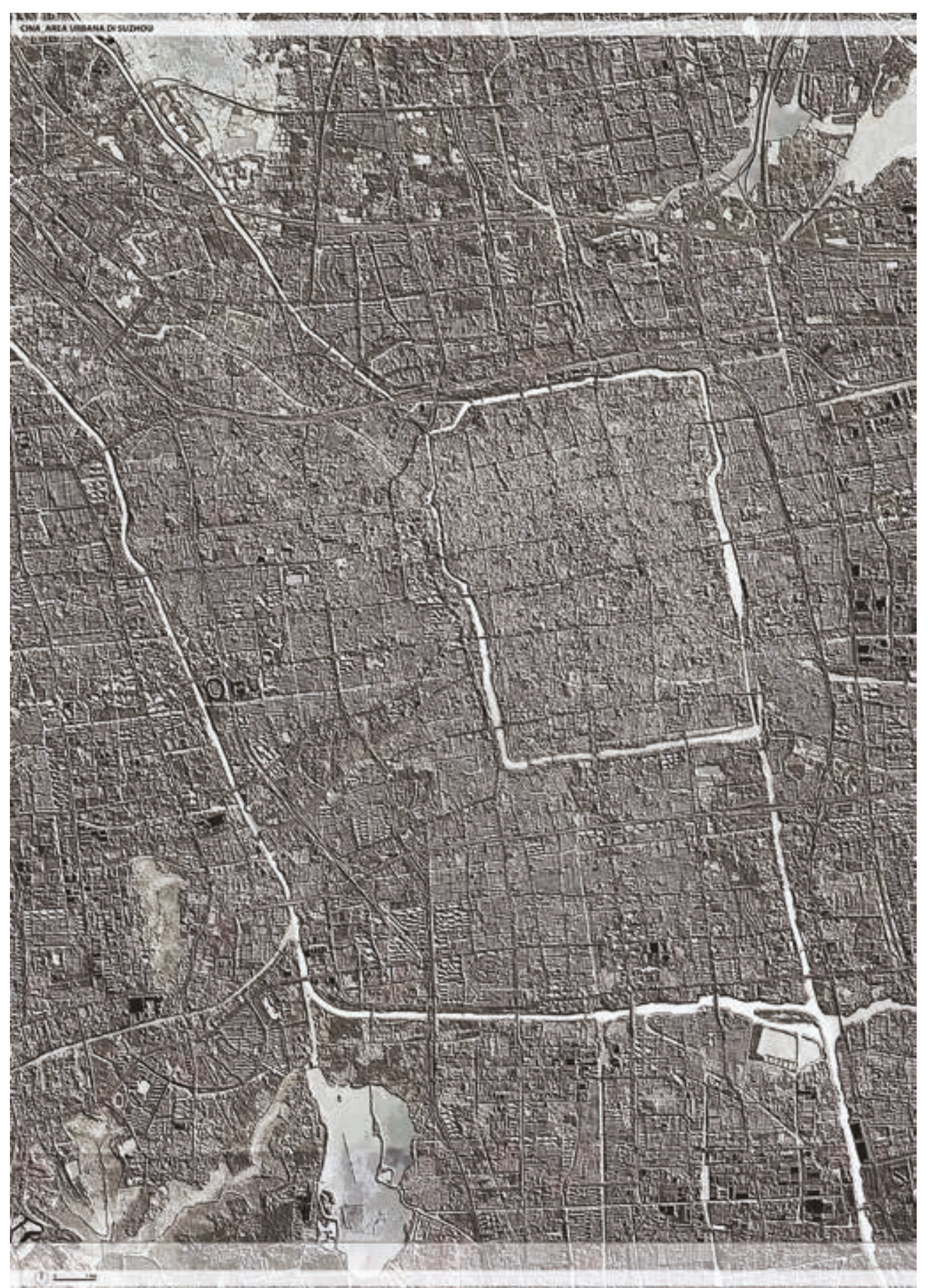

Figure 6. Context 1, typical urban area. Top view.

\section{Context 1: Urban Sprawl}

The urban objective is to contain the expansion caused by new migratory influxes for existing cities located in the vicinity of the Grand Canal and to improve urban quality through the establishment of a large network of focused projects in the most vulnerable and degraded urban areas, such 


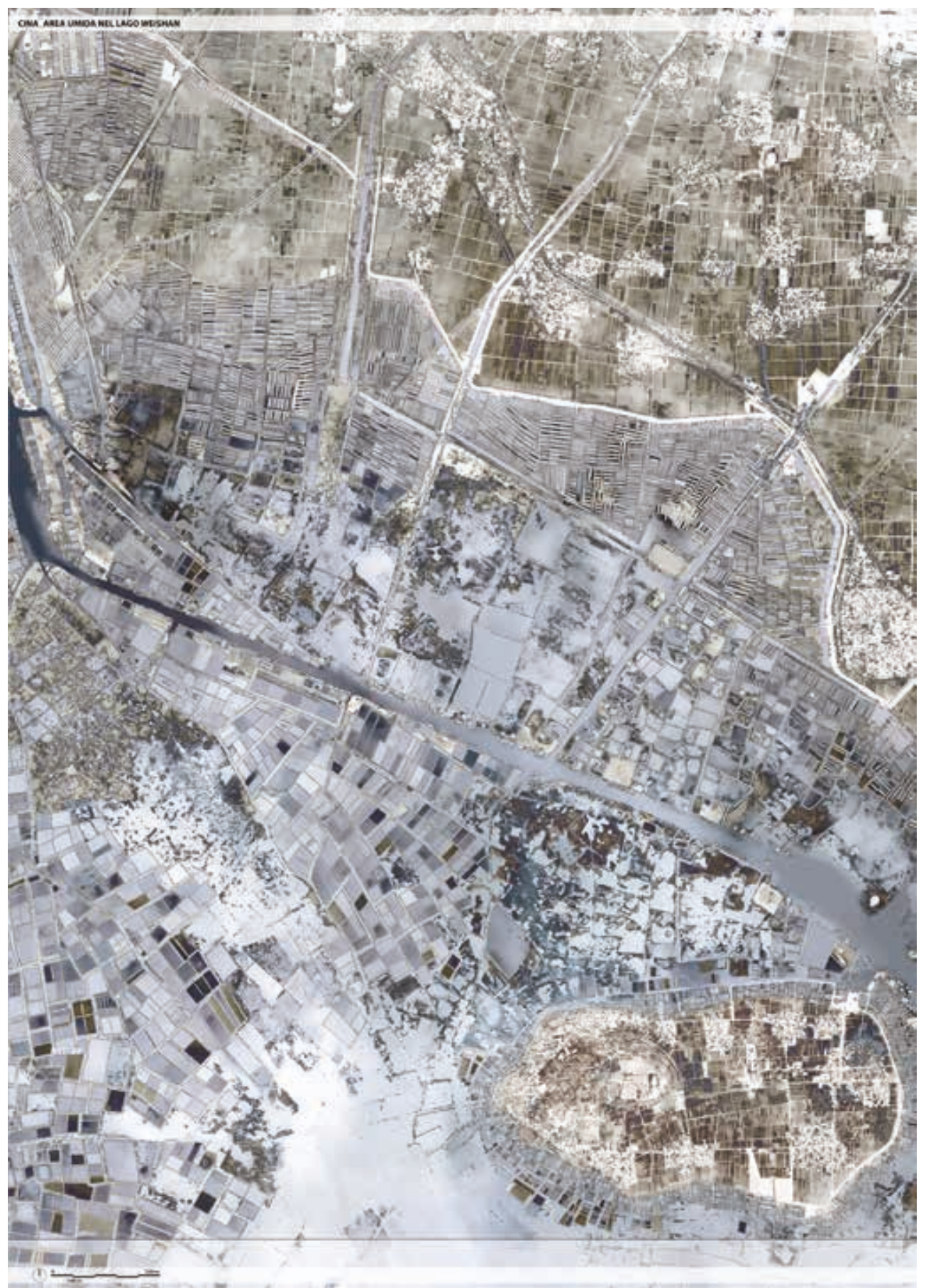

Figure 7. Context 2, typical wetland area. Top view.

as slums, abandoned and ex-industrial areas, etc. This would involve urban regeneration projects and the establishment of new green areas on reclaimed land, which would absorb greenhouse gas emissions and supply important nature areas for public recreation.

Existing green areas would be re-landscaped. Selected demolition and redevelopment would take place to provide public urban space for the 


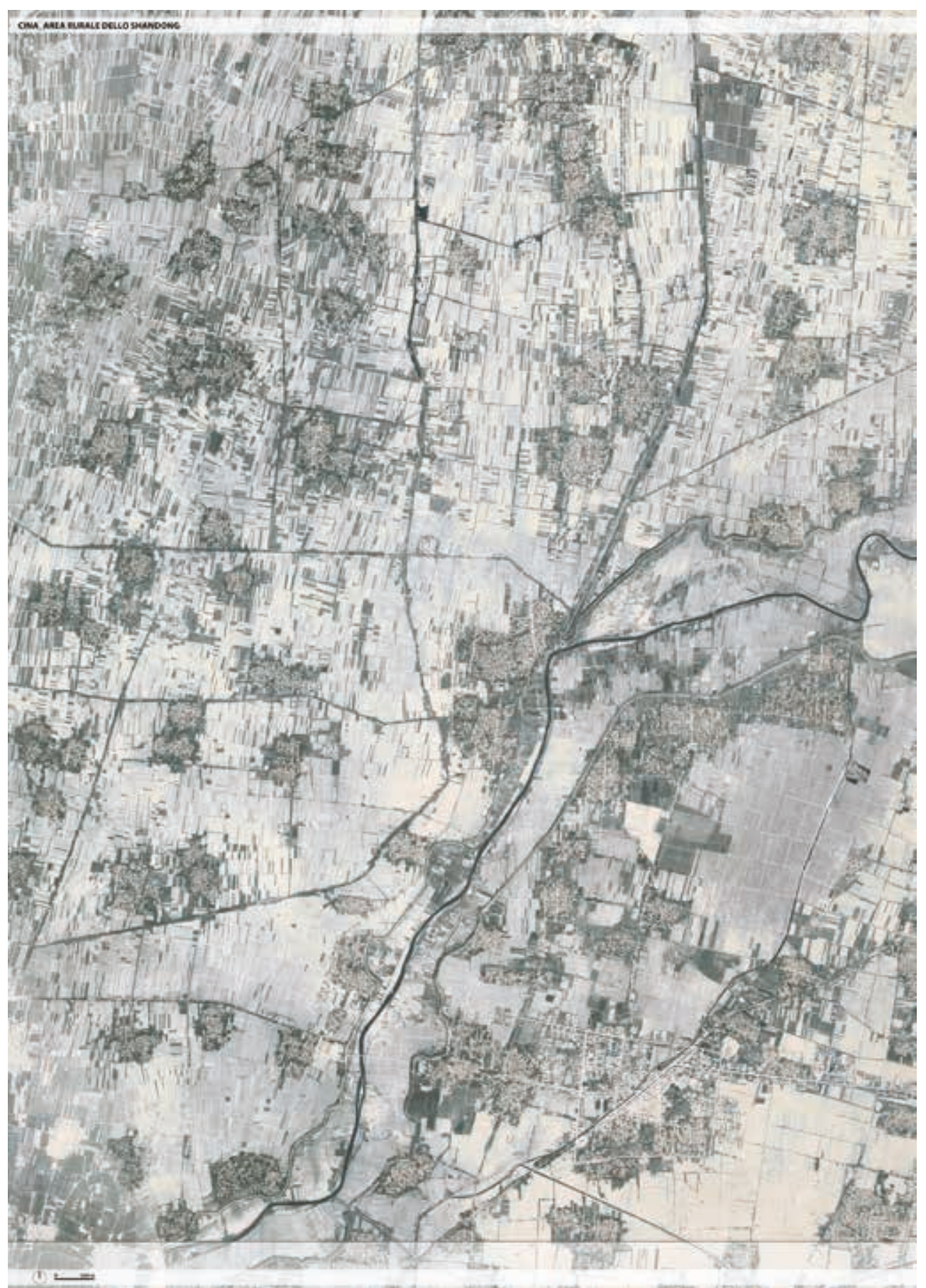

Figure 8. Context 3, typical rural area. Top view.

community. More public space would involve increasing population density in specific zones with higher office and residential buildings, which would become poles for subsidised community activity. (Figs. 9 and 10).

\section{Context 2: Water Treatment}

The aim is to exploit the great availability of water in the lakes and the wetlands along and near the Grand Canal. In the past, there were 


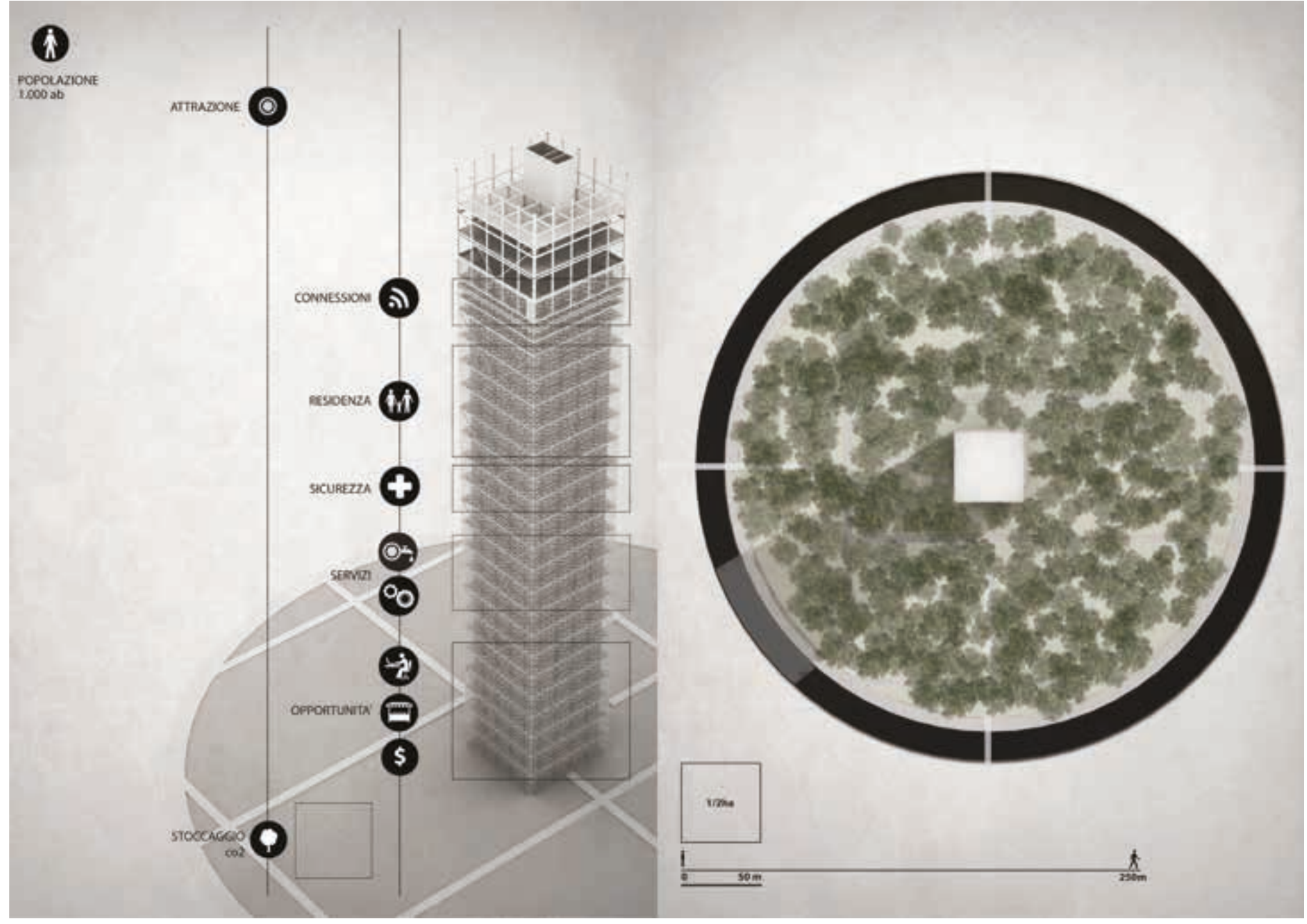

Figure 9. Urban area, typical system.

many small communities that disappeared because of the previously discussed economic and social changes. The proposal is to make it possible to establish new communities centered around future water treatments plants.

The communities would be set up using the traditional tulou, which is a single building complex occupied by all members of a small independent community. This age-old community model is still highly relevant today and offers many advantages for the effective sustainable use of shared resources. The activity necessary to establish and maintain water treatment facilities would help to sustain the community.

The advantage of this approach is that you see results earlier (as each project becomes implemented), treatment facilities can be customised to local needs with local self-management, and each area acts like a module that can be interconnected at a future date, allowing for the maximum utilization of the system. There will be enormous benefits for the environment and the remaining water-dependent fishing and rice growing communities. 


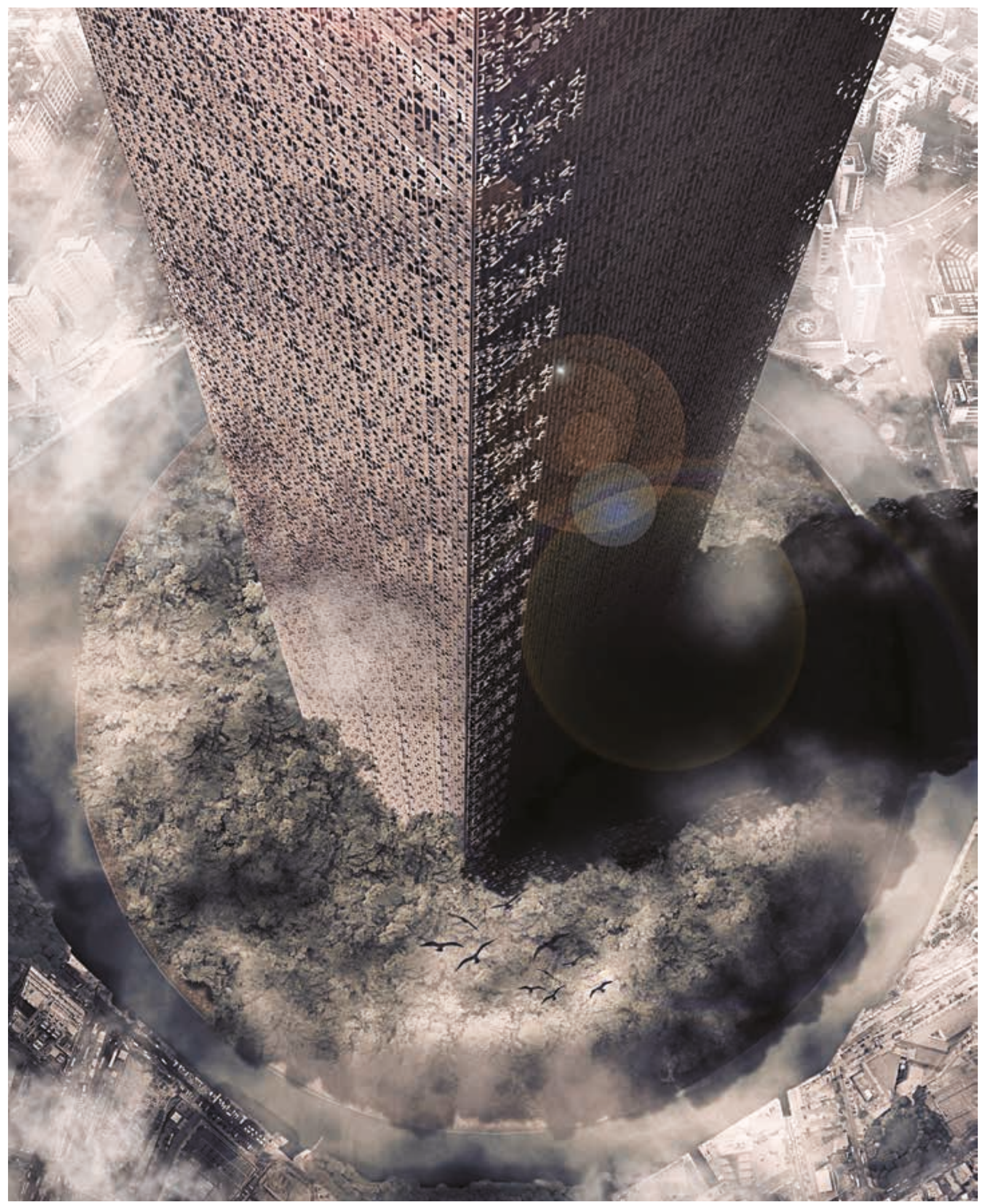

Figure 10. 2100 urban area view. 


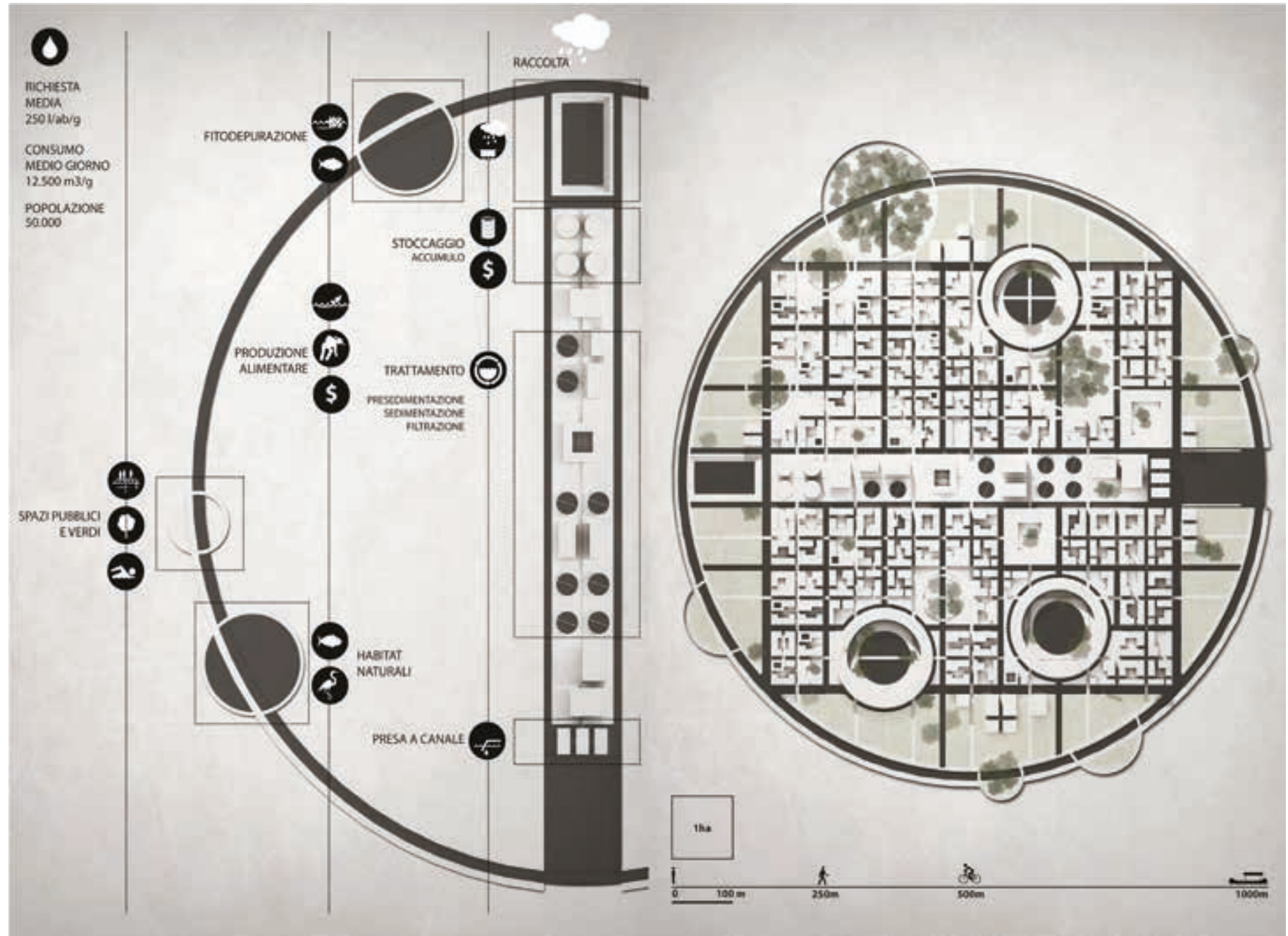

Figure 11. Wetland area, typical system.

The positive impact of this proposal would be felt in more distant areas, which would now have access to clean water, energy and available resources from recently established communities, therefore encouraging other settlements to be created. (Figs. 11 and 12).

\section{Context 3: Energy Production}

The plan is to use the energy produced by the power of the constant currents of the river for existing and potential agricultural areas, minimizing the use of energy from the main power grid. Other power sources would be wind energy, which is ideal in the vast flat areas adjacent to the canal and photovoltaic systems providing solar energy. This would result in increasing energy accessibility in both urban and rural areas and reducing carbon emissions.

Because flooding has repeatedly, over the centuries in this areas, caused significant damage to communities and agriculture seriously threatening 


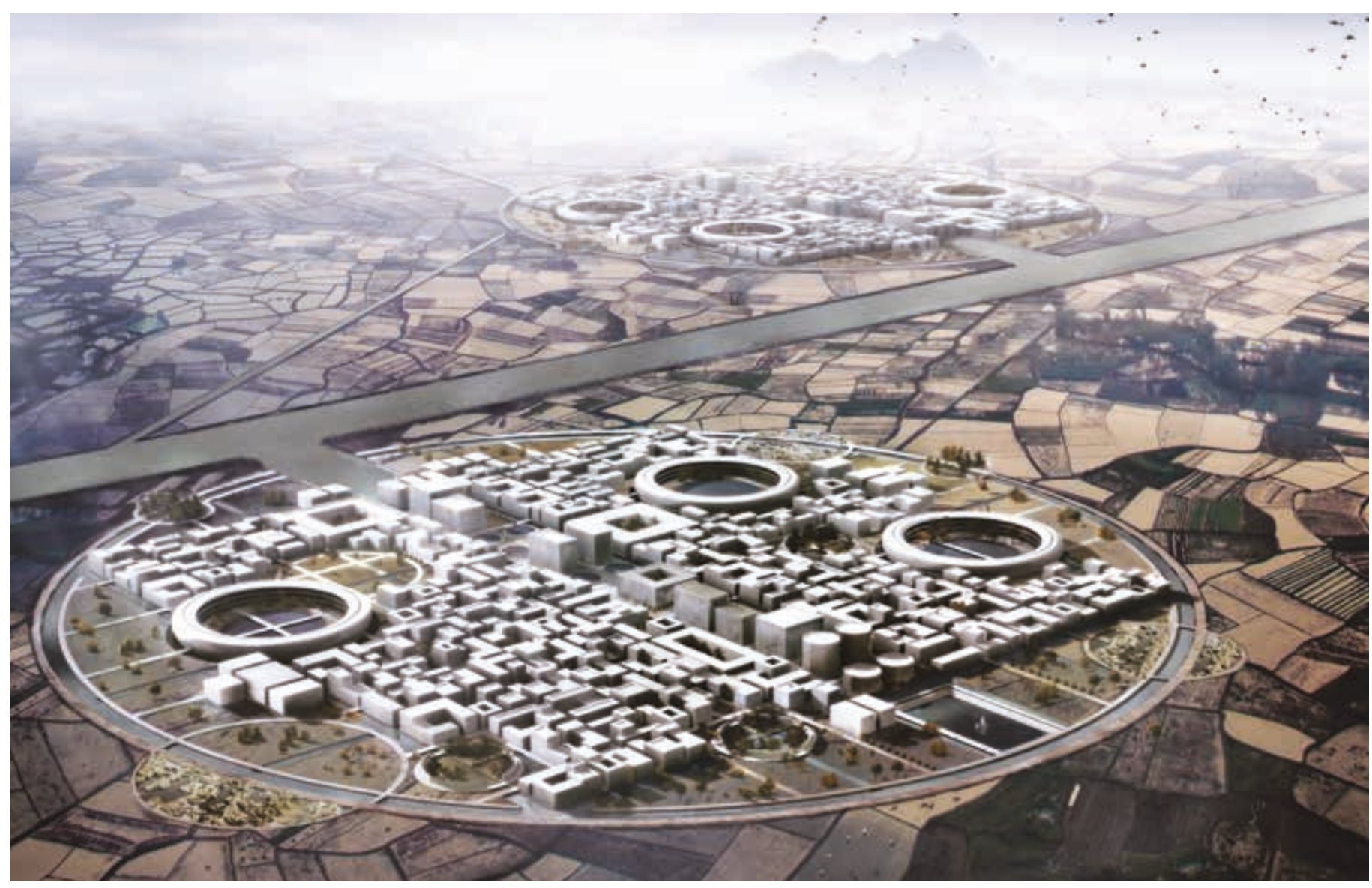

Figure 12. 2100 wetland area view.

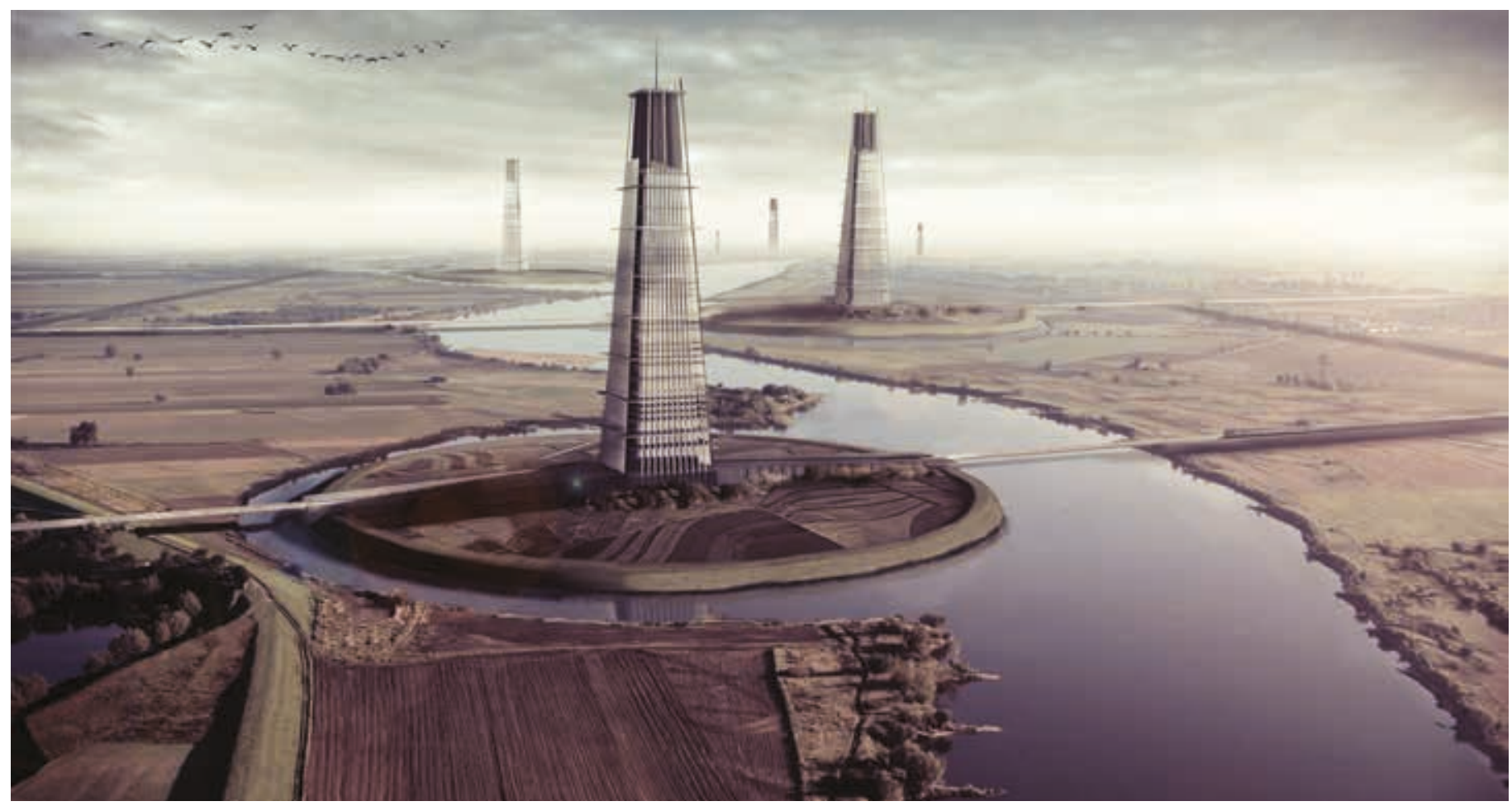

Figure 13. 2100 rural area view. 


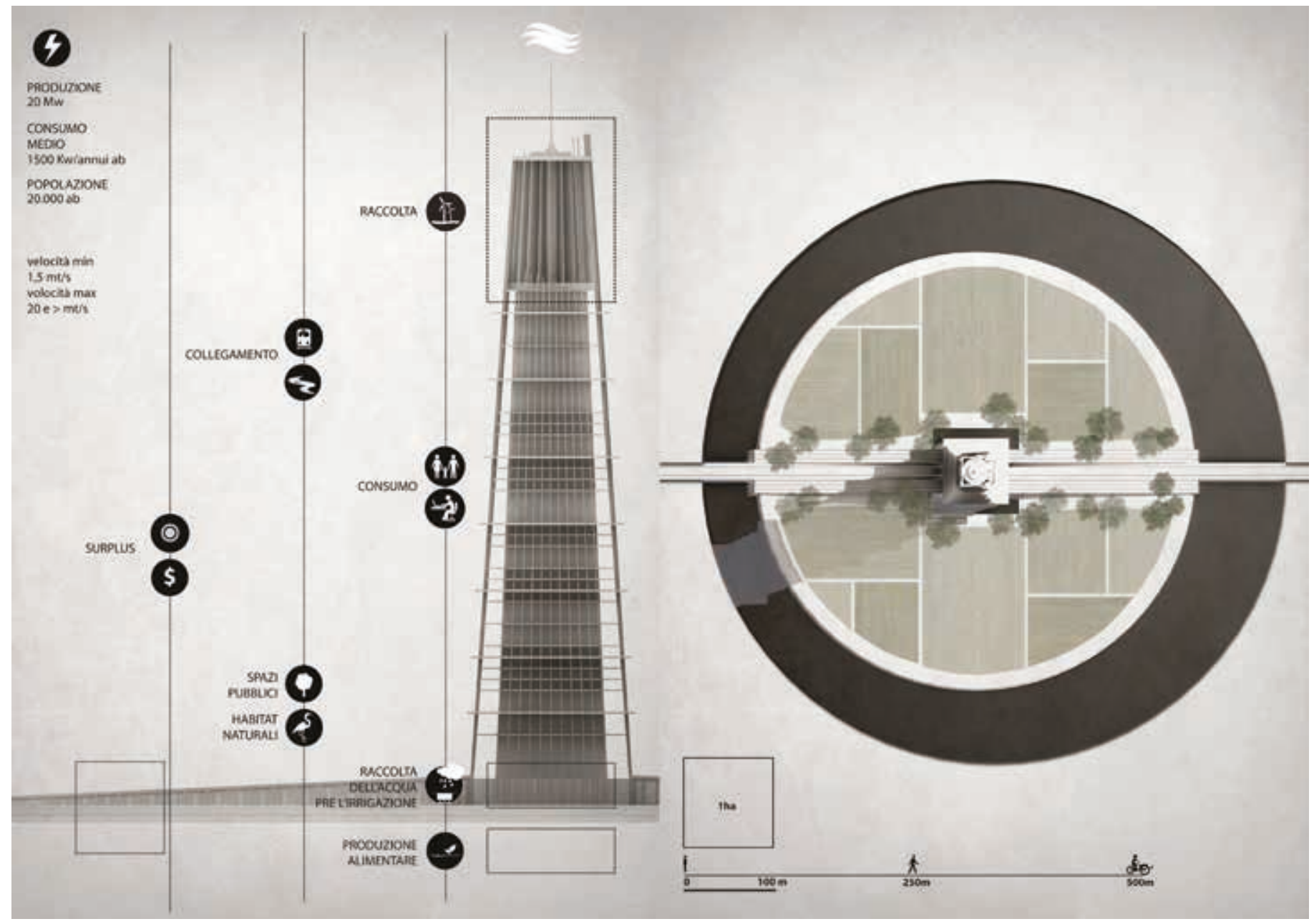

Figure 14. Rural area, typical system.

the very existence, a flood control projects will be initiated to not only protect communities but also to safeguard local energy production facilities. Soil excavated from the canal will be used for embankment reinforcement and enlargement. In this way local communities will be incentivised to settle near the water to take advantage of the proposed system. (Figs. 13 and 14).

This article was awarded First Prize at the 2015 THE PLAN Best Paper Award contest. - Ed. 


\section{References}

\section{ON VENICE}

Maretto, Paolo. La casa veneziana nella storia della città: dalle origini all'ottocento, $3^{\text {rd }}$ ed. Venice, It.: Marsilio, 1989.

Moltedo, Guido. Welcome to Venice. Venice, It.: Consorzio Venezia Nuova, 2007.

Tentori, Federico. Imparare da Venezia. Como, It.: Officina, 1994.

Salvadori, Antonio. Venice: Guide to the Principal Buildings, History of Architecture and Urban Form. Venice, It.: Canal \& Stamperia, 1995.

Trincanato, Egle R. La casa veneziana delle origini ed altri scritti sulla casa veneziana. Venice, It.: Edizioni Stamperia Cedit, 1999.

\section{ON CHINA}

Carroll, Peter J. Between Heaven and Modernity: Reconstructing Suzhou, 1895-1937. Stanford, CA (USA): Stanford University Press, 2006.

Chen, Congzhou. On Chinese Gardens. Translated by Xu Zengtong. Shanghai: Tongji University Press, 1984.

Esherick, W. Joseph ed. Remaking the Chinese City: Modernity and National Identity, 19001950. Honolulu, HI: University of Hawaii Press, 2000.

Ferguson, James R. "Suzhou: A Cultural and Economic Centre of Southern China." Culture Mandala: The Bulletin of the Centre for East-West Cultural and Economic Studies 3 (2): article 8, 1999. Available at: http://epublications.bond.edu.au/cm/vol3/iss2/8.

Gazzola, Luigi. La casa della fenice: la città e la casa nella cultura architettonica cinese. Rome: Diagonale, 1999.

Golany, Gideon S. Urban Design Ethics in Ancient China. New York: E. Mellen Press, 2001.

Guo, Qinghua. Chinese Architecture and Planning: Ideas, Methods, Techniques. London: A. Menges, 2005.

Huang, Lei, Xiao Di Zhu, and Xinsheng Zhang. "Housing Development in the Context of the Modernization, Urbanization and Conservation of Chinese Traditional Cities: Beijing, Shanghai and Suzhou," unpublished Doctor of Design Thesis. Cambridge, MA (USA): Harvard University, 2000.

Keswick, Maggie. The Chinese Garden: History, Art and Architecture. London: Academy Editions, 1986.

Lynch, Kevin. The Image of the City. Cambridge, MA (USA): M.I.T. Press, 1960.

Pang, Wai Ki. "Urban Morphology of Traditional Chinese Cities in the Context of Modernization: A Case Study of Suzhou." 42 nd ISOCARP (International Society of City and Regional Planners) Congress, 2006.

Prentice, Kaplan H. Suzhou: Shaping an Ancient City for the New China: An EDAW/Pei Workshop. Washington, D.C.: Spacemaker, 1998.

Xiaolong, Luo and Jianfa Shen. "Why City-region Planning Does not Work Well in China: The Case of Suzhou-Wuxi-Changzhou." Cities 25, no. 4 (2008).

$\mathrm{Xu}$, Yinong. The Chinese City in Space and Time: The Development of Urban Form in Suzhou. Honolulu, HI: University of Hawaii, 2000. 


\section{Credits}

Graphic works by Andrea Degli Angeli, 2014.

\section{Acknowledgements}

This article was developed from the author's Final Thesis at the IUAV, Istituto Universitario di Architettura in Venice (Italy), presented in March 2014. The preparatory study and research for the thesis were done under the supervision of Prof. Benno Albrecht.

Andrea Degli Angeli has received his professional degree in architecture from the IUAV, Istituto Universitario di Architettura in Venice (Italy), where he specialized in sustainability, with a focus on the relationships between architecture and sustainable urban planning. His studies focused on resource management, sustainable development and the architectural uses of combined high- and low-tech applications. Andrea is now based in London, where he works for Foster and Partners as an architect. He is a member of ARB/UK since 2015. E-mail: a.degliangeli@hotmail.it 
